\title{
National Ignition Facility SubSystem Design Requirements Target Area Auxiliary Subsystem SSDR 1.8.6
}

\author{
T. Reitz
}

October 20, 1996

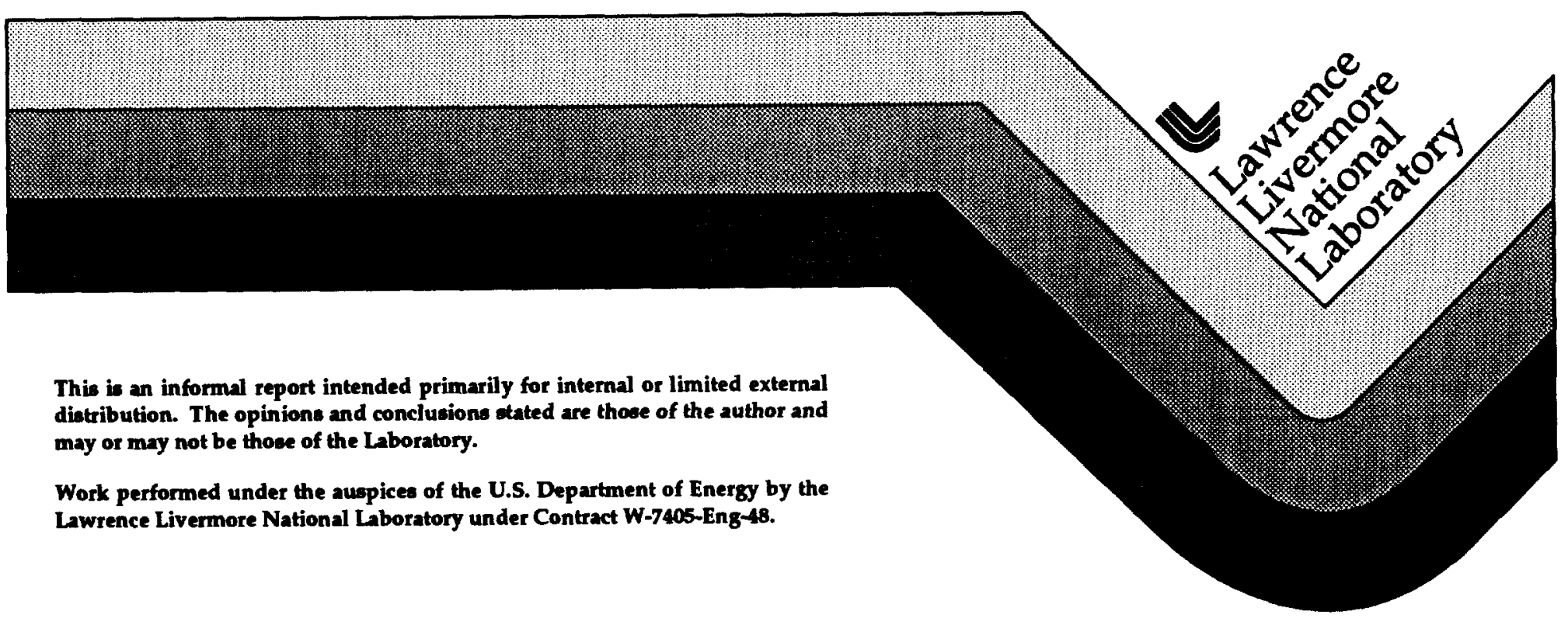




\section{DISCLAIMER}

This document was prepared as an account of work sponsored by an agency of the United States Government. Neither the Urited States Government nor the University of California nor any of their employees, makes any warranty, express or implied, or assumes any legal liability or responsibility for the accuracy, completeness, or usefulness of any information, apparatus, product, or process disclosed, or represents that its use would not infringe privately owned rights. Reference herein to any specific commercial product, process, or service by trade name, trademark, manufacturer, or otherwise, does not necessarily constitute or imply its endorsement, recommendation, or favoring by the United States Government or the University of California. The views and opinions of authors expressed herein do not necessarily state or reflect those of the United States Covernment or the University of Califorria, and shall not be used for advertising or product endorsement purposes.

This report has been reproduced directly from the best available copy.

Available to DOE and DOE contractors from the Office of Scientific and Technical Information P.O. Box 62, Oak Ridge, TN 37831

Prices available from (615) 576-8401, FTS 626-8401

Available to the public from the National Technical Information Service

U.S. Department of Commerce

5285 Port Royal Rd., Springfield, VA 22161 
NIF-0000617-B

WBS 1.8.6

\section{National Ignition Facility}

\section{Subsystem Design Requirements}

\section{Target Area Auxiliary Subsystem \\ SSDR 1.8.6}

Revision B

20 October, 1996

Prepared by:

T. Reitz, Target Area Auxiliary Systems Lead Engineer

Date

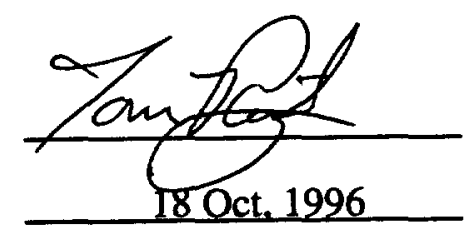

Reviewed:

V. Karpenko, Target Experimental System Engineer

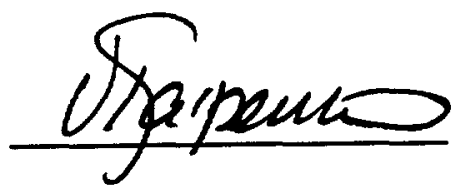

Date

18 Oct. 1996

R. Sawicki, NIF Special Equipment APE

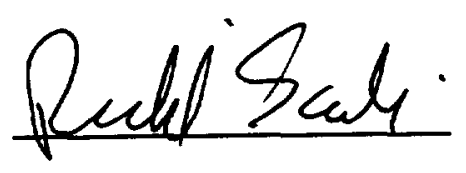

Date

18 Oct. 1996

Level 4 Configuration Control Board Approval:

S. Kumpan, NIF Project Engineer

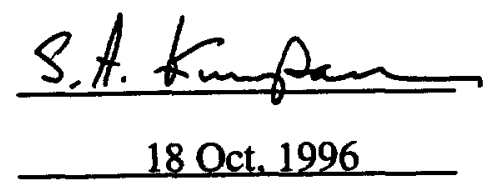




\section{Table of Contents}

\begin{tabular}{|c|c|}
\hline Paragraph & Title \\
\hline 1.0 & Scope \\
\hline 2.0 & Applicable Documents \\
\hline 2.1 & Applicable NIF Project Documents \\
\hline 2.1 .1 & Interface Control Documents \\
\hline 2.2 & Applicable US Government Orders, Codes, and Standards \\
\hline 2.2 .1 & DOE Regulations \\
\hline 2.2 .2 & Other Government Regulations \\
\hline 2.3 & Applicable National Consensus Codes and Standards \\
\hline 2.4 & Applicable LLNL Standards \\
\hline 3.0 & Requirements and Verification \\
\hline 3.1 & Subsystem Definition \\
\hline 3.1 .1 & Subsystem Description \\
\hline 3.1 .1 .1 & Local Utility Services Description \\
\hline 3.1 .1 .2 & Cable Trays Description \\
\hline 3.1 .1 .3 & Personnel, Safety, and Occupational Access Description \\
\hline 3.1 .1 .4 & Assembly, Installation, and Maintenance Equipment Description \\
\hline 3.1.1.4.1 & Target Chamber Service System Description \\
\hline 3.1.1.4.2 & Target Bay Service Systems Description \\
\hline 3.1 .2 & Subsystem Functions \\
\hline 3.1.2.1 & Local Utility Services Functions \\
\hline 3.1 .2 .2 & Cable Trays Functions \\
\hline 3.1.2.3 & Personnel, Safety, and Occupational Access Functions \\
\hline 3.1 .2 .4 & Assembly, Installation, and Maintenance Equipment Functions \\
\hline 3.1.2.4.1 & Target Chamber Service System Functions \\
\hline 3.1.2.4.2 & Target Bay Service Systems Functions \\
\hline 3.1 .3 & System Diagrams \\
\hline 3.1.3.1 & Local Utility Services Diagrams \\
\hline 3.1.3.1.1 & Electrical Utility Services Diagram \\
\hline 3.1.3.1.2 & Network Utility Services Diagram \\
\hline 3.1.3.1.3 & Gas Utility Services Diagram \\
\hline 3.1.3.1.4 & Liquid Utility Services Diagram \\
\hline 3.1.3.2 & Cable Trays Diagram \\
\hline 3.1.3.3 & Personnel, Safety, and Occupational Access Diagrams \\
\hline 3.1.3.3.1 & Transport Pathways Diagram \\
\hline 3.1.3.3.2 & Oxygen and Carbon Dioxide Monitoring Diagram \\
\hline 3.1 .3 .4 & Assembly, Installation, and Maintenance Equipment Diagrams \\
\hline 3.1.3.4.1 & Target Chamber Service System Diagram \\
\hline 3.1.3.4.2 & Target Bay Service Systems Diagram \\
\hline 3.1 .4 & System Interfaces \\
\hline 3.1.4.1 & Local Utility Services Interfaces \\
\hline 3.1 .4 .2 & Cable Tray Interfaces \\
\hline 3.1 .4 .3 & Personnel, Safety, and Occupational Access Interfaces \\
\hline 3.1 .4 .4 & Assembly, Installation, and Maintenance Equipment Intertaces \\
\hline 3.1 .4 .4 .1 & $\begin{array}{l}\text { Target Chamber Service System Intertaces } \\
\text { Target Bay Service Systems Interfaces }\end{array}$ \\
\hline 1.4 .4 .2 & $\begin{array}{l}\text { Target Bay Service Systems mteriaces } \\
\text { Major Subsystems }\end{array}$ \\
\hline 3. & System Characteristics and Verification \\
\hline & Performance Characteristics \\
\hline & Local Utility Service Performance \\
\hline .1 .1 .1 & Local Utility Neutron Activation \\
\hline
\end{tabular}




\section{Table of Contents}

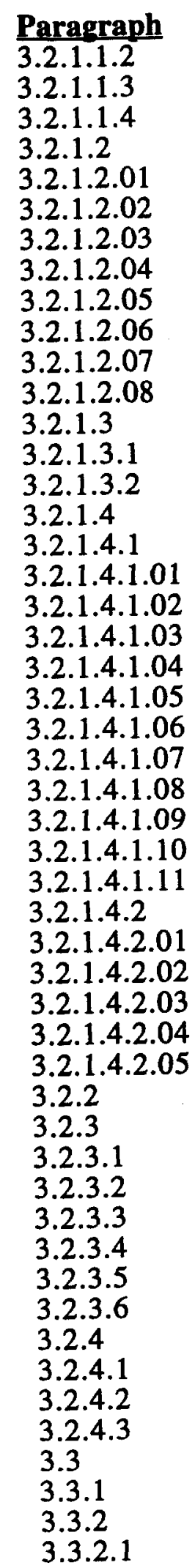

\section{Title}

Local Utility Safety

Local Utility Grounding

Local Utility Shield Wall Penetrations

Cable Tray Performance

Cable Tray Neutron Activation

Cable Tray Electo-Magnetic Shielding

Cable Tray Security

Cable Tray Bandwidth

Cable Tray Safety

Cable Tray Grounding

Cable Tray Cable Types

Cable Tray Shield Wall Penetrations

Personnel, Safety, and Occupational Access Performance

Oxygen and Carbon Dioxide Monitoring

Transport Pathways

Assembly, Installation, and Maintenance Equipment Performance

Target Chamber Service System Performance

Target Chamber Cleaning

Target Chamber Vacuuming

First Wall Panel Removal and Replacement

Beam Dump Maintenance

Remote Chamber Video Inspection

Man Lift Chamber Access

Plenum Cover Installation

Facility Considerations

Remote Operation

Construction / Maintenance

Lift Storage / Installation

Target Bay Service Systems Performance

Final Optics Assembly Transport

Beam Tube Transport

Diagnostic Transport

First Wall Panel Transport

LRU Adjacencies

Physical Characteristics

Reliability, Availability, Maintainability (RAM)

Lifetime

Replaceability

Reliability

Inherent Availability

Maintainability

Recovery From Abnormal Events

Environmental

Ambient Temperature/Humidity

Ambient Vibration

Ambient Cleanliness

Design and Construction

Hazard Classification

Safety

Life Safety 


\section{Table of Contents}

Paragraph

3.3.2.2

3.3.2.3

3.3.2.4

3.3.3

3.3.4

3.3.5

3.3 .6

3.3.7

3.3.8

3.4

3.4 .1

3.4 .2

3.5

3.6

4.0

4.1

4.2

4.3

5.0

6.0

\section{Title}

Construction \& Occupational Safety

Fail-Safe Design

Robotic Systems Safety

Human Factors

Supervisory Software Access to Distributed Control Points Documentation and Records

Design Process

Future Modifications and Upgrades

Decontamination and Decommissioning

Logistics

Spare Equipment

Maintenance Equipment

Other

Major Component Characteristics and Verification

QA Provisions

Q-Level Assigned

Quality Requirements

Quality Assurance Measures (verification requirements)

Notes

Revision Record 
1.0 Scope

This Subsystem Design Requirement (SSDR) establishes the performance, design, development, and test requirements for the Target Area Auxiliary Subsystems (WBS 1.8.6), which is part of the NIF Target Experimental System (WBS 1.8). This document responds directly to the requirements detailed in NIF Target Experimental System SDR 003 document.

Key elements of the Target Area Auxiliary Subsystems include:

WBS 1.8.6.1 Local Utility Services

WBS 1.8.6.2 Cable Trays

WBS 1.8.6.3 Personnel, Safety, and Occupational Access

WBS 1.8.6.4 Assembly, Installation, and Maintenance Equipment

WBS 1.8.6.4.1 Target Chamber Service System

WBS 1.8.6.4.2 Target Bay Service Systems

\subsection{Applicable Documents}

This section lists DOE orders, codes, and standards which are applicable to the Target Area Auxiliary Subsystems. The applicable portions of these documents apply. Applicable LLNL standards are also being considered contingent upon the decision of final site selection.

\subsection{Applicable NIF Project Documents}

- NIF-LLNL-93-058, L-15983-3, NIF Functional Requirements and Primary Criteria, Revision 1.4, February 1996

- NIF-LLNL-96-227, L-21706-02, NIF System Design Requirements, Target Experimental System, SDR-003 Revision 2, August 1996

- NIF-LLNL-93-044, L-15958-1, NIF Quality Assurance Program Plan, November 1993

- NIF-LLNL-94-017, L-15958-5, NIF Ancillary Software Quality Assurance Plan, January 1994

- NIF-LLNL-95-599, L-20523-1, NIF Environmental, Safety, and Health Management Plan, November 1995

- NIF-LLNL-94-211, L-17346-1, NIF Grounding, Shielding, and Isolation Plan,

- NIF-LLNL-96-038, L-21248-01, "Proposed Metrication Policy for NIF", memo from R. Sawicki, January 1996

- UCRL-ID-118202, "Radiation and EMI Effects in the NIF Environment",

\subsubsection{Interface Control Documents}

Interface requirements between WBS subsystems are controlled through separate Interface Control Documents (ICD's). See the document control system for the complete listing and the most recent revision of each of these documents.

\subsection{Applicable US Government Orders, Codes, and Standards}

\subsubsection{DOE Regulations}

The following DOE regulations are specifically referenced in this document, and are applicable to the Target Area Auxiliary Subsystem.

- DOE Order 420.1, Facility Safety

- DOE Order 440.1, Worker Protection Management for DOE Federal and Contractor Employees.

- DOE Order 5700.6C, Quality Assurance

- DOE Standard 1020-94, Natural Phenomena Hazards Design and Evaluation Criteria for DOE Facilities 


\subsubsection{Other Government Regulations}

The following government regulations are specifically referenced in this document, and are applicable to the Target Area Auxiliary Subsystem.

- 29 CFR 1910, Occupational Safety and Health Act (OSHA)

- 29 CFR 1926, Occupational Safety and Health Act (OSHA)

\subsection{Applicable National Consensus Codes and Standards}

The following national consensus standards are generally applicable to NIF, some are specified in the Functional Requirements and Primary Criteria, but not all are specifically referenced in this document. These national consensus standards are assumed to apply to some section of the Target Area Auxiliary Subsystem, until determined otherwise.

$\begin{array}{ll}\text { ANSI } & \text { - American National Standards Institute, } \\ \text { ASME } & \text { - American Society of Mechanical Engineers, } \\ \text { ASTM } & \text { - American Society for Testing and Materials, } \\ \text { IEEE } & \text { - Institute of Electrical and Electronics Engineers, } \\ \text { EIA } & \text { - Electronic Industries Association, } \\ \text { ISA } & \text { - Instrument Society of America, } \\ \text { NEMA } & \text { - National Electrical Manufacturers Association, } \\ \text { NFPA } & \text { - National Fire Protection Association, } \\ \text { RIA } & \text { - Robotic Industries Association }\end{array}$

- ANSU/ASME B1.1, Standard for Bolt Threads

- ANSI/NFPA 70, National Electrical Code (NEC)

- ANSI/NFPA 79, Electrical Standard for Industrial Machinery

- ANSINFPA 101, Life Safety Code

- ANSUIEEE 488.1 488.2, Standard Digital Interface for Programmable Instrumentation

- ANSI/RIA R15.01 1990, American National Standard for Industrial Robots and Robot Systems Common Identification Methods for Signal and Power Carrying Conductors

- ANSIRIA R15.02 1990, American National Standard for Industrial Robots and Robot Systems Hand Held Robot Control Pendants - Human Engineering Design Criteria

- ANSIRIA R15.06 1992, American National Standard for Industrial Robots and Robot Systems Safety Requirements

- ASTM A307, Standard Specification for Carbon Steel Bolts and Studs, 60,000 psi Tensile Strength

- ASTM A325, Standard Specification for High Strength Bolts for Structural Steel Joints

- ASTM A36, Standard Specification for Structural Steel

- ASTM A449, Standard Specification for Quenched and Tempered Steel Bolts and Studs

- ASTM A490, Standard Specification for Heat Treated Steel Structural Bolts, 150 ksi Minimum Tensile Strength

- ASTM A6, Chemical Analysis for Structural Steel

- ASTM A751 F606, Testing Methods for Bolts and Studs

- ASTM D3951, Packaging of Bolts and Studs

- ASTM A563 F568, Appurtenances for Structural Steel (Nuts and Bolts)

- EIA RS-232 RS-422 RS-423 RS-485, Serial Interface Standards

- IEEE 802.3, Local Area Network for Data Communications

- ISA S5.1, Instrumentation Symbols and Identification

- ISA S5.5, Graphics Symbols for Process Displays

- NEMA ICS6, Enclosures for Industrial Control Systems 


\subsection{Applicable LLNL Standards}

Pending final site selection, the following LLNL standards generally apply to NIF, and are assumed to apply to the Target Area Auxiliary Subsystem until determined otherwise.

- LLNL Committee on Metrification, "LLNL Metric Transition Path", October 1992

- LLNL M-012 Rev 7, "Design Safety Standards - Mechanical Engineering”, February 1993

- LLNL M-010, "Health and Safety Manual", September 1990

- LLNL, "Hazards Control Manual"

- LLNL M-256, "Mechanical Engineering Design Practice"

- LLNL, "Mechanical Engineering Policy Procedures Manual"

- LLNL, LED 43-20-01-A10, "Electronics Engineering Standard - Documentation, Engineering and Design Quality, and Configuration Management", April 1994

\subsection{Requirements and Verification}

\subsection{Subsystem Definition}

The Target Area Auxiliary Subsystems (WBS 1.8.6) are defined as the required utility services to support the target chamber, target bay, and diagnostic building. The Target Area Auxiliary Subsystems will:

- Provide and route utility services

- Provide and route cable trays

- Provide for personnel safety and occupational access

- Provide service equipment required for inner target chamber maintenance

- Provide service equipment required for target bay maintenance

\subsubsection{Subsystem Description}

The Target Area Auxiliary Subsystems (WBS 1.8.6) consists of the following elements:

\subsubsection{Local Utility Services Description}

The Local Utility Services (WBS 1.8.6.1) will provide and route all electrical, network, gas, and liquid utility services to all the required target area systems. Utility services will be required for the diagnostic systems, final optics assemblies, turning mirrors, beam tubes, vacuum system, tritium processing system, robotic system, and other target area systems.

\subsubsection{Cable Trays Description}

The Cable Trays (WBS 1.8.6.2) will provide and route metallic cable trays for the transport of data and control signals to all the required target area systems. Cable tray systems will be required for the diagnostics, final optics assemblies, turning mirrors, and other auxiliary systems. The diagnostic cable tray system will be routed from each diagnostic in the target bay to one of the four diagnostic switch yard enclosures. The final optics assembly and turning mirror cable tray systems will be routed from each final optics assembly and each turning mirror in the target bay to one of the four alignment switch yard instrumentation rack sets. The auxiliary cable tray system will route cable trays for other target area systems in the target bay and diagnostic building. 


\subsubsection{Personnel, Safety, and Occupational Access Description}

The Personnel, Safety, Occupational Access (WBS 1.8.6.3) will provide safe transport pathways into and out of the target area for the occupational access of personnel and equipment to the many different systems in the target area which must be maintained.

An oxygen and carbon dioxide monitoring system will also be provided for personnel safety in the NIF target areas involving carbon dioxide and other asphyxiant gases for operations. The oxygen and carbon dioxide monitors will service the target chamber, target bay, diagnostic building, and EPS basement as required. The oxygen and carbon dioxide monitor system will provide room monitors with audible and visual alarms. In addition to local readouts and alarms the monitor outputs will be available to the NIF Safety Interlock System.

The neutron and gamma monitoring system will be provided for in WBS 1.8.5.5 The tritium monitoring system will be provided for in WBS 1.8.5.7.

\subsubsection{Assembly, Installation, and Maintenance Equipment Description}

The Assembly, Installation, and Maintenance Equipment (WBS 1.8.6.4) consists of the following elements:

\subsection{Target Chamber Service System Description}

The Target Chamber Service System (WBS 1.8.6.4.1) is comprised of the chamber lift, robotic manipulator, and robot end effectors. The chamber lift is integrated into the target chamber pedestal support. The robotic manipulator will be mounted to the chamber lift through an opening in the target chamber pedestal support; and will then enter the target chamber through an opening at the bottom of the target chamber at the pedestal support interface. The robotic end effectors are each designed to accomplish a different task. The combination of the chamber lift, robotic manipulator, and robotic end effectors will provide the means of servicing the inner chamber, which is considered a hostile environment which requires the use of robotic automation. The robotic manipulator unit will be housed in the basement of the NIF diagnostic building.

\subsection{Target Bay Service Systems Description}

The Target Bay Service Systems (WBS 1.8.6.4.2) will be designed to access and engage the FOA, beam tube, and diagnostic line replaceable units (LRU's), lift them from there normally mounted position, and move them to a transport cart. The lifting equipment and fixtures will be designed for specific tasks, consequently, each LRU will require a separate engagement fixture and various lifting mechanisms may be employed. Commonality between lifting equipment and fixtures is a design goal. The target bay service systems is also responsible for transporting debris shields and first wall panels within the target area.

\subsubsection{Subsystem Functions}

The Target Area Auxiliary Subsystems (WBS 1.8.6) will provide the following capabilities:

\subsubsection{Local Utility Services Functions}

The function of the Local Utility Services (WBS 1.8.6.1) is to provide and route services to all the target area systems. The major utility services which need to be routed in the target area are:

- Electrical Services: Utility power, Research Power, Backup Power

- Network Services: Ethernet, ATM

- Gas Services: Compressed Air, Dry Air, Nitrogen, Carbon Dioxide, Helium

- Liquid Services: Low Conductivity Water, Cooling Water, Liquid Nitrogen 


\subsubsection{Cable Trays Functions}

The function of the Cable Trays (WBS 1.8.6.2) is to provide data and signal cable pathways to all the target area systems. The major target area systems which need cables routed are:

- Final Optics Assemblies

- Turning Mirrors (LM-6, LM-7, LM-8)

- Target Positioner

- Diagnostics

- Vacuum Systems

\subsubsection{Personnel, Safety, and Occupational Access Functions}

The function of the Personnel, Safety, and Occupational Access (WBS 1.8.6.3) is to provide for personnel safety and safe occupational access in and around the target area. The major personnel, safety, and occupational access tasks are:

- Transport Pathways (between Target Bay, Switch Yard, Diagnostic Building, Outside)

- Oxygen Monitors

- Carbon Dioxide Monitors

\subsubsection{Assembly, Installation, and Maintenance Equipment Functions}

The Assembly, Installation, and Maintenance Equipment (WBS 1.8.6.4) will provide the following capabilities:

\subsection{Target Chamber Service System Functions}

The function of the Target Chamber Service System (WBS 1.8.6.4.1) is to provide the means of servicing the inner target chamber, which is considered a hostile environment that requires the use of automation. The system will accomplish the following major service tasks:

- Target Chamber Cleaning (fixed contamination and debris)

- Target Chamber Vacuuming (loose contamination and debris)

- First Wall Panel Removal and Replacement

- Beam Dump Maintenance

- Remote Chamber Inspection (remote video)

- Man Lift Chamber Access

- Plenum Cover Installation

\subsection{Target Bay Service Systems Functions}

The function of the Target Bay Service Systems (WBS 1.8.6.4.2) is to facilitate the removal and replacement of line replaceable units (LRU's) in the target bay. The major LRU's in the target bay are:

- FOA Integrated Optics Module (IOM)

- FOA Debris Shields

- Beam Tubes

- Diagnostic Equipment

- First Wall Panels 


\subsubsection{System Diagrams}

\subsubsection{Local Utility Services Diagrams}

\subsection{Electrical Utility Services Diagram}

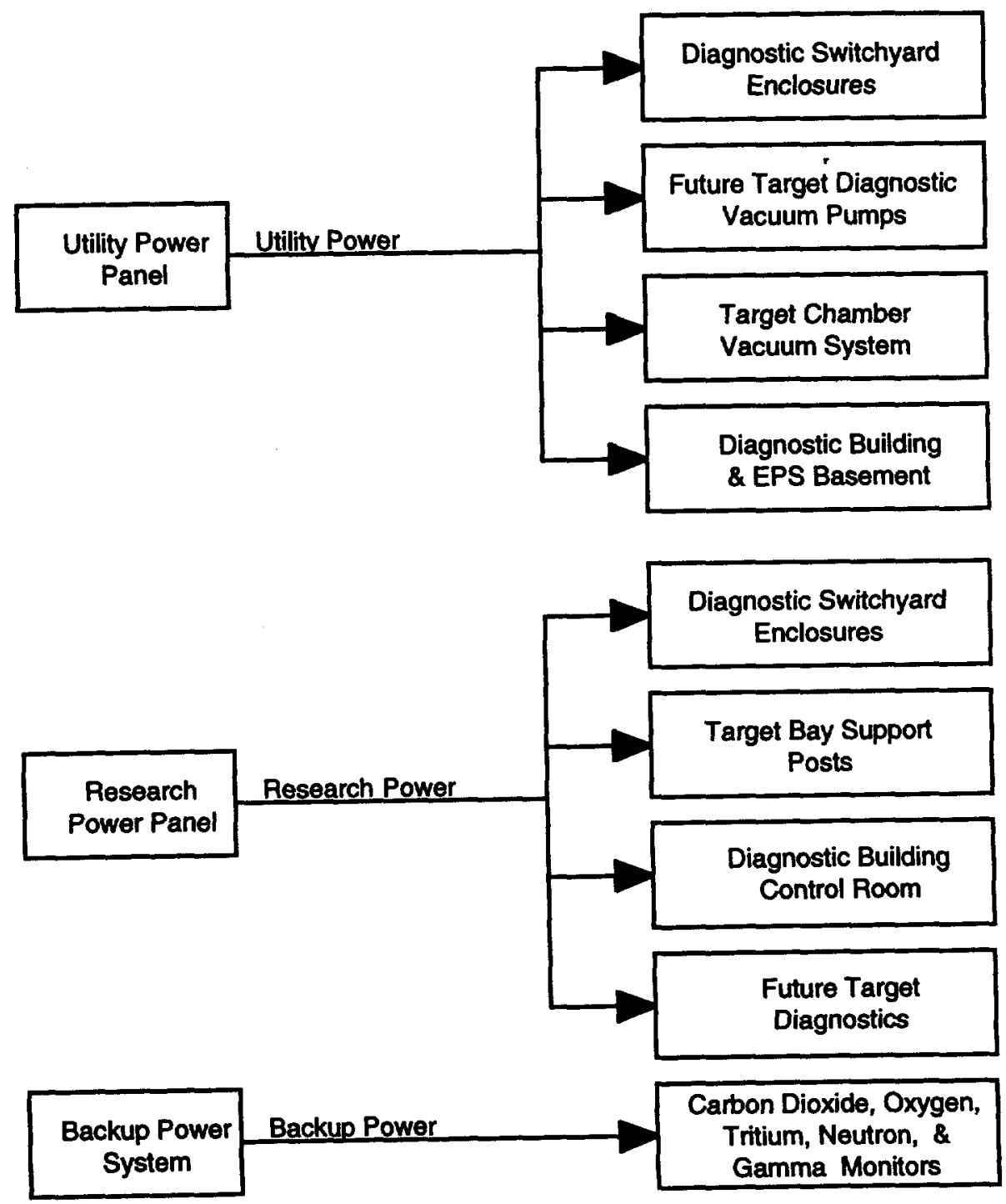

Figure 3.1.3.1.1 Electrical Utility Services Flow Diagram 
3.1.3.1.2

Network Utility Services Diagram

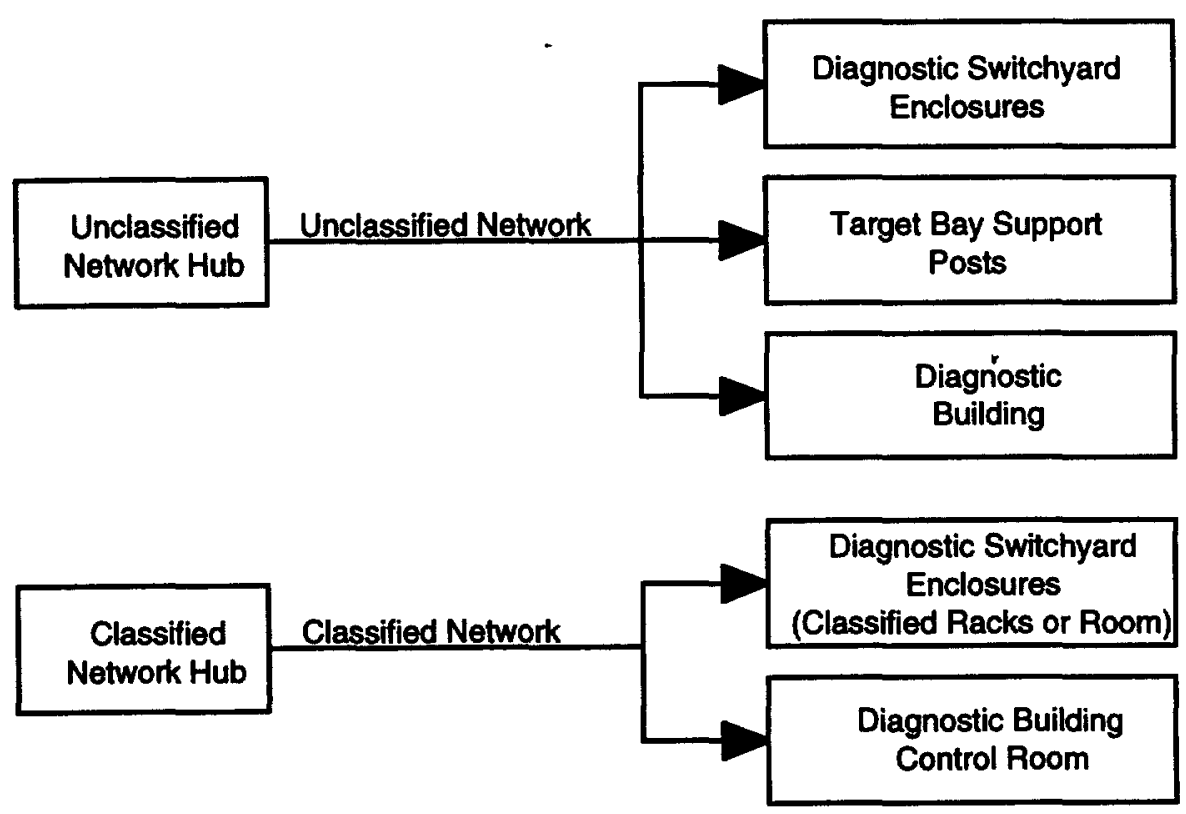

Figure 3.1.3.1.2 Network Utility Services Flow Diagram 


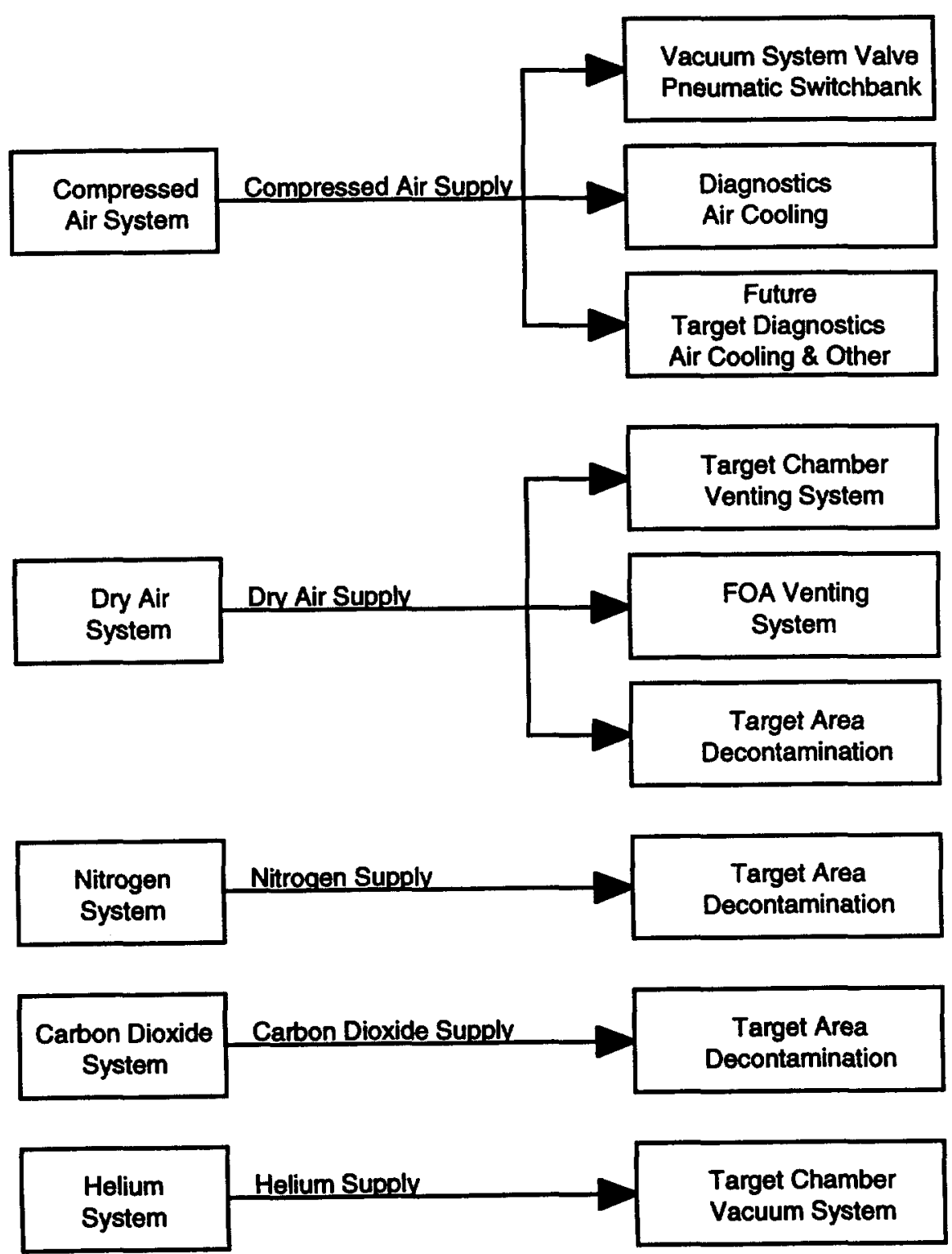

Figure 3.1.3.1.3 Gas Utility Services Flow Diagram 

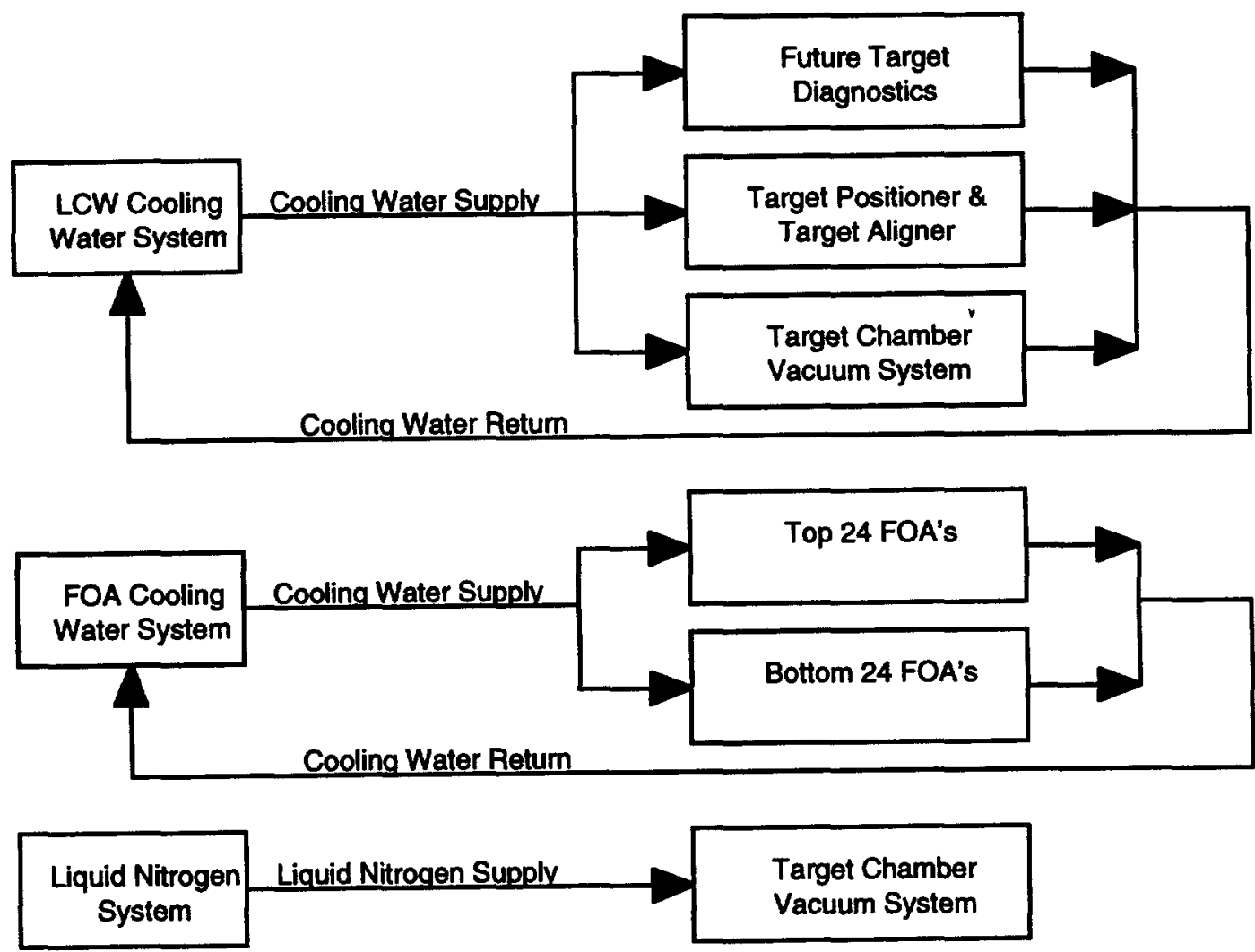

Figure 3.1.3.1.4 Liquid Utility Services Flow Diagram 


\subsubsection{Cable Trays Diagram}

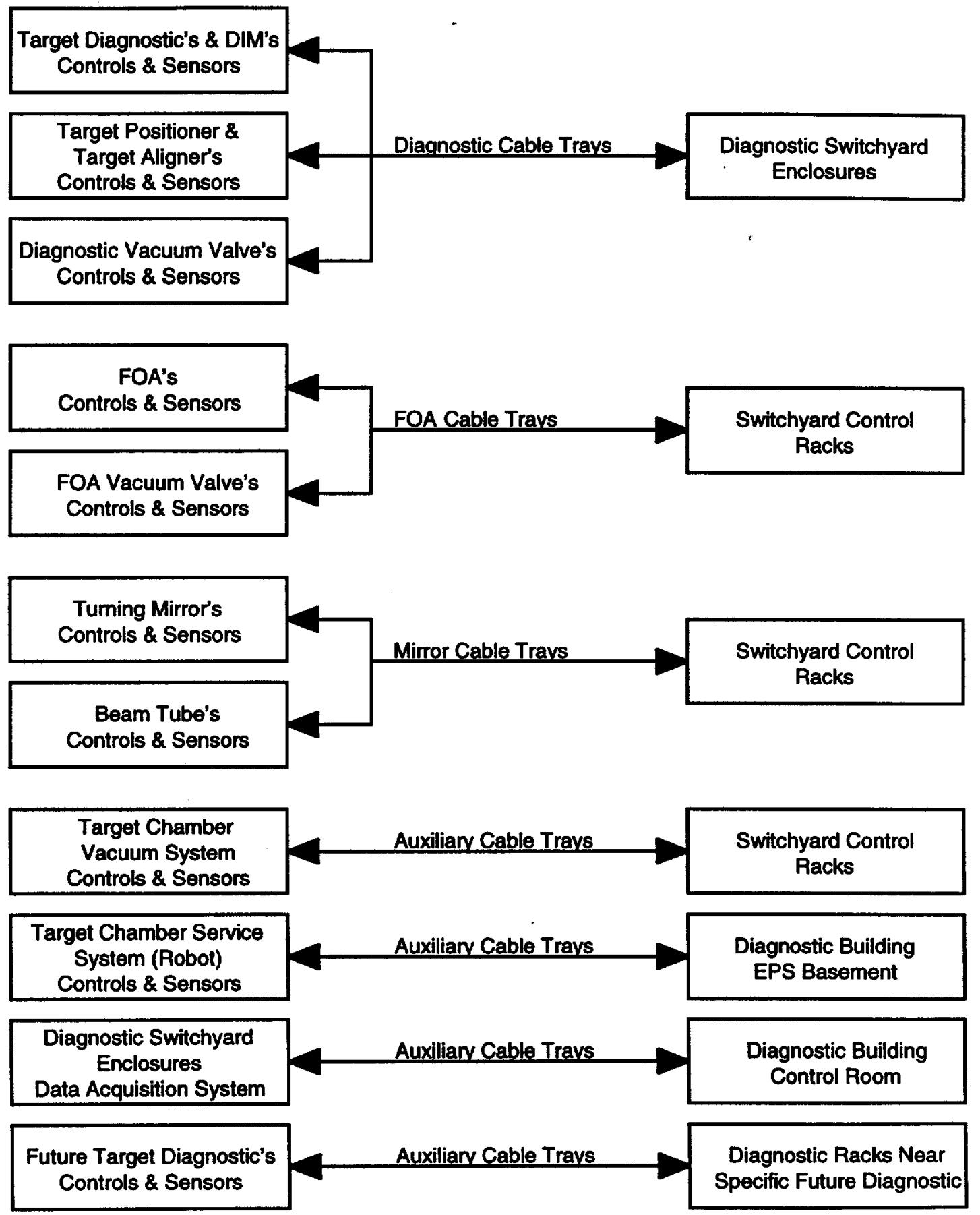

Figure 3.1.3.2 Cable Trays Flow Diagram 


\subsubsection{Personnel, Safety, and Occupational Access Diagrams}

\subsection{Transport Pathways Diagram}

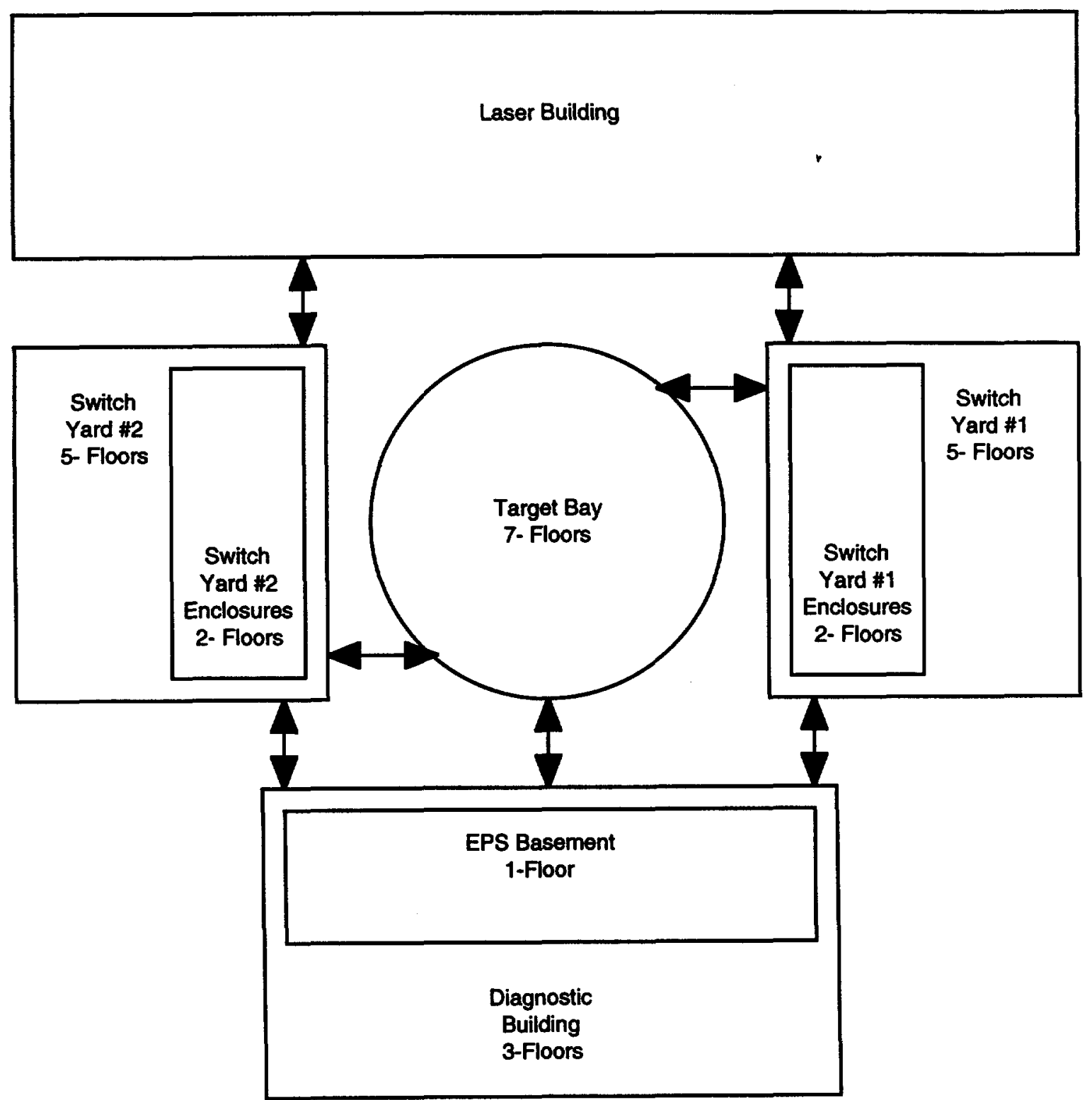

Figure 3.1.3.3.1 Transport Pathways Flow Diagram 


\subsection{Oxygen and Carbon Dioxide Monitoring Diagram}

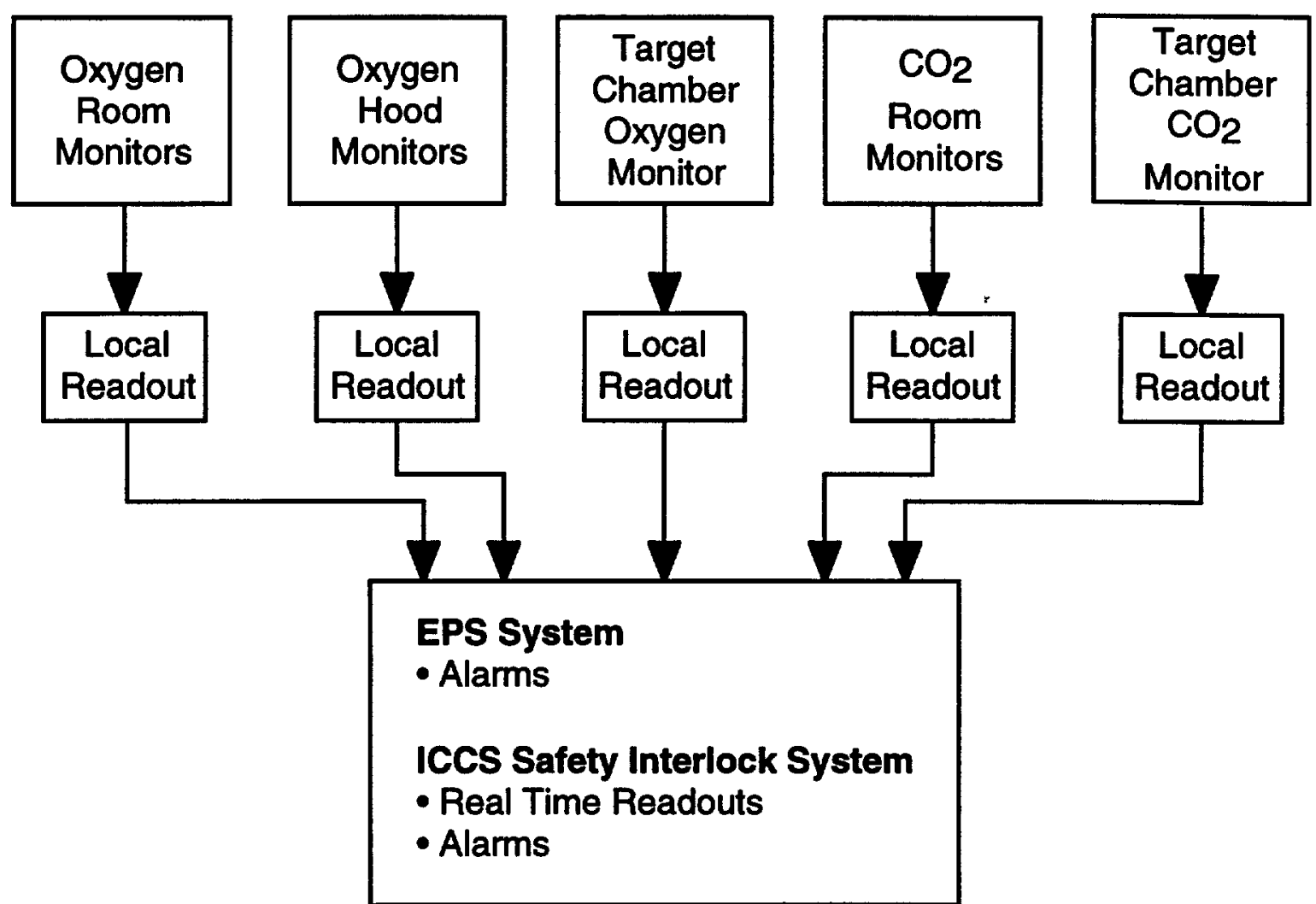

Figure 3.1.3.3.2 Oxygen and Carbon Dioxide Monitor System Flow Diagram 


\subsubsection{Assembly, Installation, and Maintenance Equipment Diagrams}

\subsection{Target Chamber Service System Diagram}

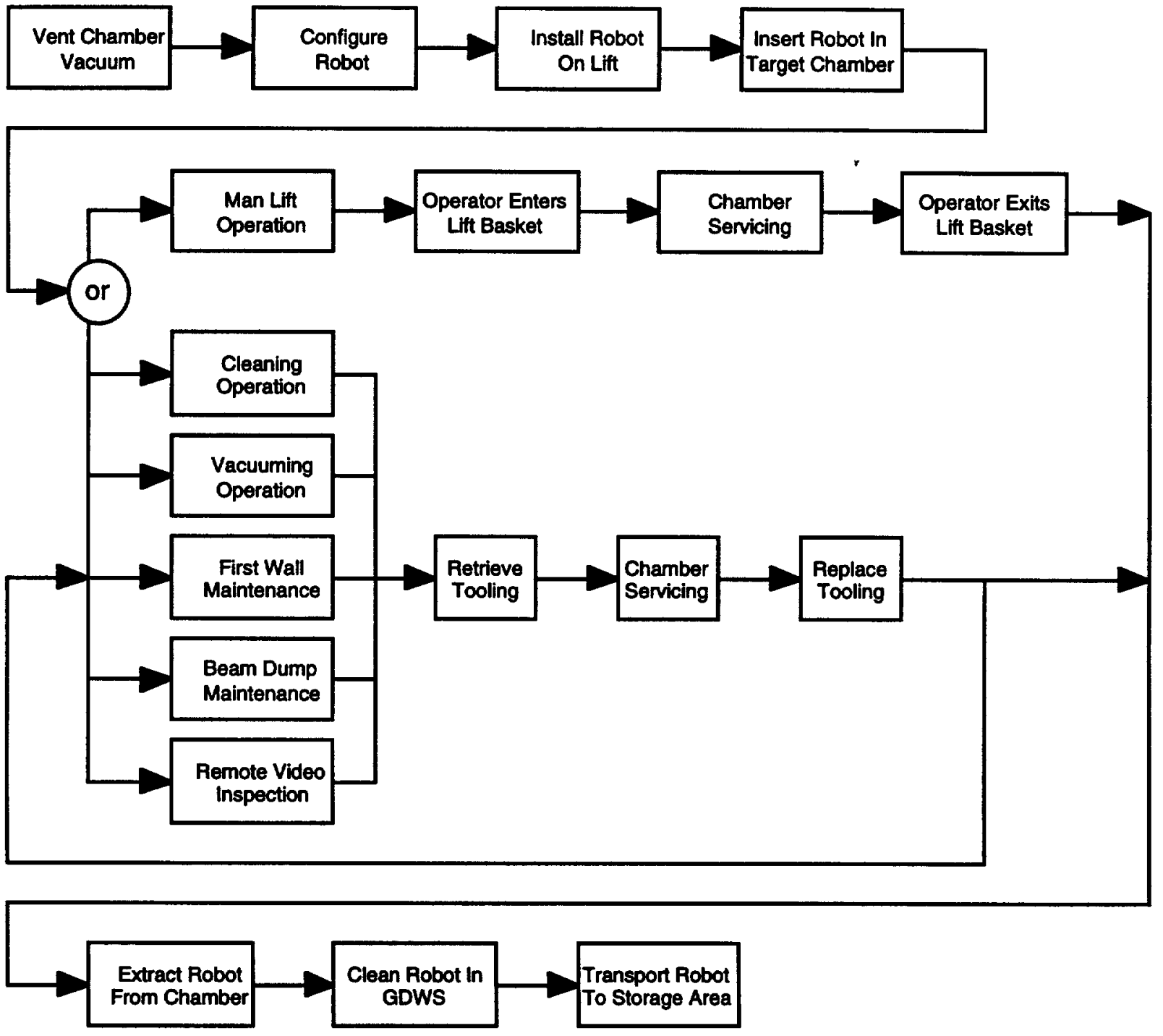

Figure 3.1.3.4.1 Target Chamber Service System Flow Diagram 


\subsection{Target Bay Service Systems Diagram}
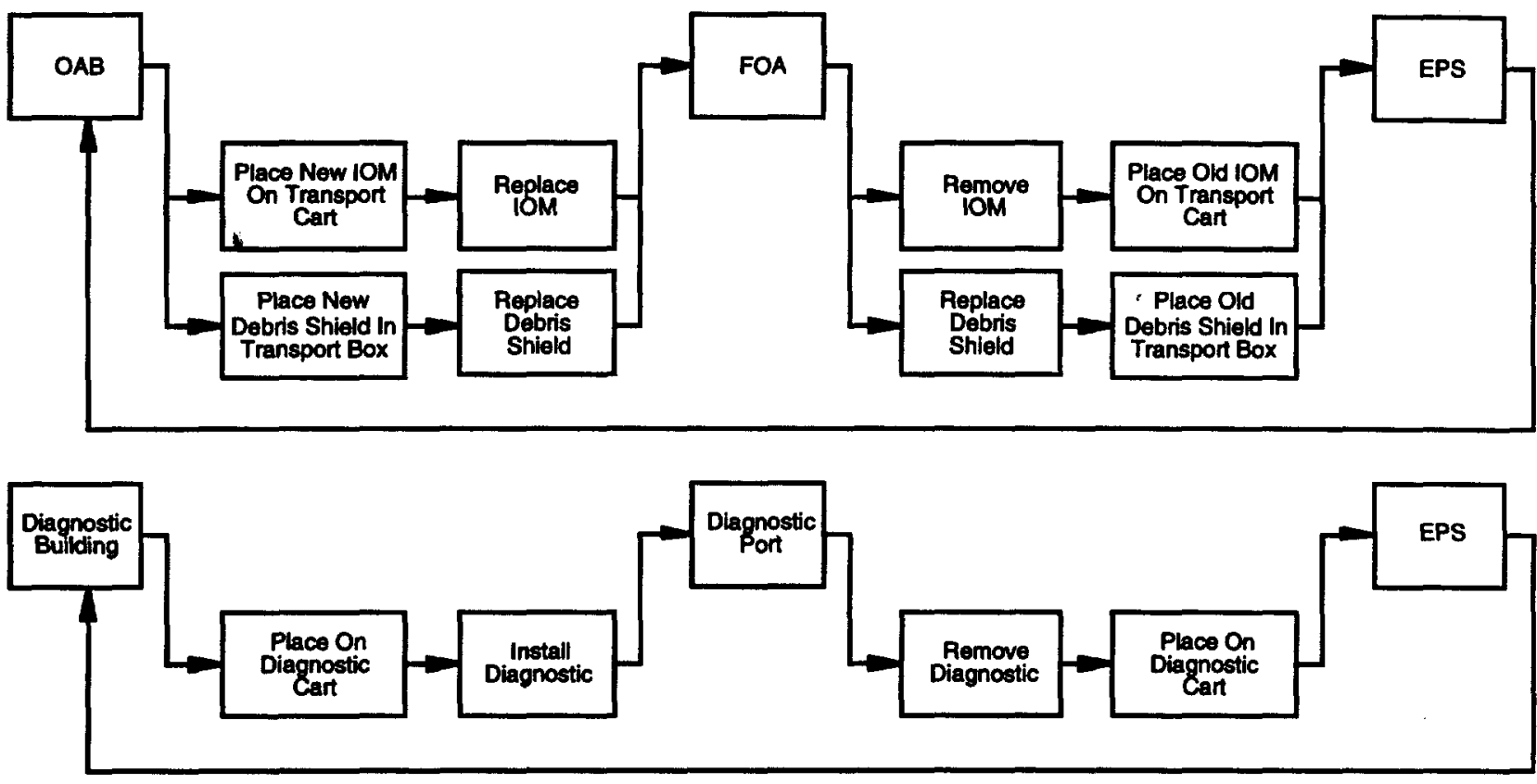

Figure 3.1.3.4.2 Target Bay Service System Flow Diagram

\subsubsection{System Interfaces}

The Target Area Auxiliary Subsystems (WBS 1.8.6) has the following principle interfaces:

\subsubsection{Local Utility Services Interfaces}

The Local Utility Services (WBS 1.8.6.1) will provide power, networking, gas and liquid utilities to all the NIF target area systems. Principal interfaces include:

- LTAB Facility

- Target Chamber Vacuum System

- FOA Vacuum System

- Diagnostic Vacuum System

- Target Inserter, Positioner

- Laser System Performance \& Verification Diagnostics

- Diagnostic Instrument Manipulator

- Target Area Data Acquisition System

- Target Area Beam Tubes

- Tritium Processing System

- Target Chamber Service System

- Target Bay Service Systems

- Final Optics Assembly

- Future Target Diagnostics Support 


\subsubsection{Cable Tray Interfaces}

The Cable Trays (WBS 1.8.6.2) will provide cable tray systems for diagnostics, final optics assemblies, turning mirrors, and other auxiliary systems in the target area. Principal interfaces include:

- LTAB Facility

- Energy Diagnostics Data System

- Target Chamber Vacuum System

- FOA Vacuum System

- Diagnostic Vacuum System

- Target Inserter, Positioner

- Laser System Performance \& Verification Diagnostics

- Diagnostic Instrument Manipulator

- Target Area Data Acquisition System

- Diagnostic EMI, EMP, and Radiation Protection

- Tritium Processing System

- Target Chamber Service System

- Target Bay Service Systems

- Final Optics Assembly

- Future Target Diagnostics Support

\subsubsection{Personnel, Safety, and Occupational Access Interfaces}

The Personnel, Safety, and Occupational Access (WBS 1.8.6.3) will provide safe transport pathways into the target area for personnel and equipment access, to the many systems in the NIF target area. Principal interfaces include:

- LTAB Facility

- ICCS Safety \& Interlocks System

- ICCS Facility Environmental Monitor

- ICCS Access Control System

- Target Chamber

- Target Area Data Acquisition System

- Tritium Processing System

- Neutron \& Gamma Monitoring System

- Tritium Monitoring System

- Target Chamber Service System

- Target Bay Service Systems 
3.1.4.4 Assembly, Installation, and Maintenance Equipment Interfaces The Assembly, Installation, and Maintenance Equipment (WBS 1.8.6.4) has the following principle interfaces:

\subsection{Target Chamber Service System Interfaces}

The Target Chamber Service System (WBS 1.8.6.4.1) will provide the target chamber lift, target chamber robot, and the tooling for each task required in the NIF target chamber. Principal interfaces include:

- LTAB Facility

- ICCS Safety \& Interlocks System

- ICCS Access Control System

- Target Chamber Ports

- Target Chamber First Wall

- Target Chamber Mechanical Structure

- Target Inserter, Positioner

- Diagnostic Instrument Manipulator

- Target Chamber Cleaning \& Decontamination

- General Decontamination Workstation

- Local Utility Services

- Cable Trays

- Final Optics Assembly

- Personnel, Safety, and Occupational Access

\subsection{Target Bay Service Systems Interfaces}

The Target Bay Service Systems (WBS 1.8.6.4.2) will provide the lifting equipment and fixtures required for each transportation task in the NIF target bay. Principal interfaces include:

- LTAB Facility

- Target Chamber First Wall Tiles

- Energy Diagnostics Data System (FOA Calorimeters)

- Target Inserter, Positioner

- Laser System Performance \& Verification Diagnostics

- Diagnostic Instrument Manipulator

- Target Area Beam Tubes

- General Decontamination Workstation

- Local Utility Services

- Cable Trays

- Final Optics Assembly (Integrated Optics Module, Debris Shield)

- Future Target Diagnostics Support

- Personnel, Safety, and Occupational Access

\subsubsection{Major Subsystems}

Not Used 


\subsection{System Characteristics and Verification}

The following sections define the minimum requirements which must be met by the Target Area Auxiliary Subsystem, related to performance characteristics. The approach for verifying that the design and the hardware meet each requirement is listed for each.

\subsubsection{Performance Characteristics}

\subsubsection{Local Utility Service Performance}

\subsection{Local Utility Neutron Activation}

The electrical, network, gas, and liquid utility systems shall minimize the usage of materials with poor neutron activation properties where possible.

\subsection{Local Utility Safety}

The electrical, network, gas, and liquid utility systems shall meet all NEC, fire safety, and site specific regulations.

\subsection{Local Utility Grounding}

The electrical, network, gas, and liquid utility systems shall meet all grounding requirements, as specified in the NIF Grounding, Shielding, and Isolation Plan.

\subsection{Local Utility Shield Wall Penetrations}

The penetrations through any radiation shield wall or other shielding structure for electrical, network, gas, and liquid utilities shall not be radially in line with the target chamber center.

\subsubsection{Cable Tray Performance}

\subsection{Cable Tray Neutron Activation}

The cable trays shall be constructed of a material that will minimize neutron activation.

\subsection{Cable Tray Electo-Magnetic Shielding}

The diagnostic cable trays shall be fully enclosed and constructed of a material that will shield against electro-magnetic interference (EMI) and electro-magnetic pulses (EMP).

\subsection{Cable Tray Security}

Select cable trays shall be able to handle classified data signal cables.

\subsection{Cable Tray Bandwidth}

Cable tray runs from target diagnostics to electronic diagnostic equipment shall be as short as possible to maximize signal bandwidth.

\subsection{Cable Tray Safety}

The cable tray systems shall meet all NEC, fire safety, and site specific regulations.

\subsection{Cable Tray Grounding}

The cable tray systems shall meet all grounding requirements, as specified in the NIF Grounding, Shielding, and Isolation Plan.

\subsection{Cable Tray Cable Types}

The cable trays shall be able to accommodate both hard wire and fiber optic cables.

\subsection{Cable Tray Shield Wall Penetrations}

The penetrations through any radiation shield wall or other shielding structure for cable trays shall not be radially in line with the target chamber center. 


\subsubsection{Personnel, Safety, and Occupational Access Performance}

\subsection{Oxygen and Carbon Dioxide Monitoring}

Provisions for monitoring oxygen and carbon dioxide gas levels for personnel safety purposes shall be made as required.

\subsection{Transport Pathways}

Provisions for transport pathways in the target area (target chamber, target bay, switch yard, and diagnostic building) shall be made as required.

\subsubsection{Assembly, Installation, and Maintenance Equipment Performance}

\subsection{Target Chamber Service System Performance}

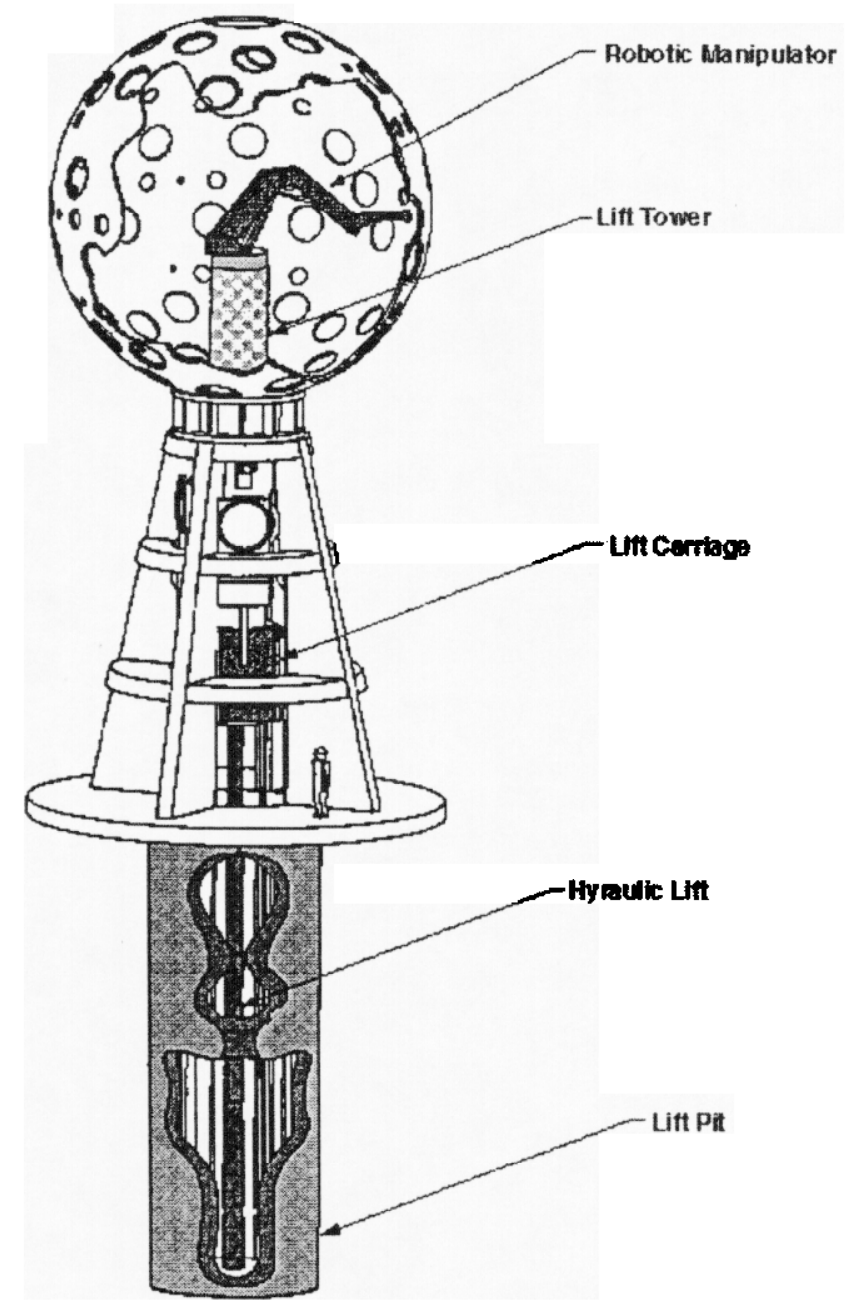

Figure 3.2.1.4.1 Preliminary Target Chamber Service System 


\subsection{Target Chamber Cleaning}

The robot system shall be capable of handling a cleaning system to facilitate cleaning of fixed debris and deposits from the first wall tiles. The robot shall be capable of manipulating the cleaning end effector within the entire inner target chamber space. The system shall run in autonomous mode during this operation.

\subsection{Target Chamber Vacuuming}

The robot system shall be capable of handling a vacuuming system to facilitate cleaning loose debris from within the inner target chamber. The robot shall be capable of manipulating the vacuum end effector within the entire inner target chamber space. The system shall run in autonomous mode during this operation.

\subsection{First Wall Panel Removal and Replacement}

The robot system shall be capable of first wall removal and replacement within the target chamber. This will include grasping the tile, unfastening the tile from the chamber, placing the tile at a chamber port for extraction, retrieving a new tile, placing and fastening the new tile to the chamber wall. The robot will be run primarily in autonomous mode but other manual modes shall be provided to allow for accommodation of off-normal situations.

\subsection{Beam Dump Maintenance}

The robot system should be capable of beam dump maintenance. This may include removal and replacement within the target chamber similar to the first wall maintenance. The robot will be run primarily in autonomous mode but other manual modes shall be provided to allow for accommodation of off-normal situations.

\subsection{Remote Chamber Video Inspection}

The robot system shall be capable of remote chamber video inspection. The vision system will give the operator and robot controller a means of inspecting the target chamber interior without a human entering the chamber. The inspection head shall consist of multiple cameras and lighting which shall be controlled from the control room. Some inspection capabilities may be included on other robot tools in addition to the video head. The robot shall be run in autonomous or teleoperated mode in this operation. 


\subsection{Man Lift Chamber Access}

The system shall be capable of acting as a man lift to access the target chamber interior. A man basket will allow operators with tooling to be positioned at all locations within the target chamber. The operators may enter the chamber with the lift or from a side port as safety allows. The system will be controlled in manual joint mode from the lift basket during this operation.

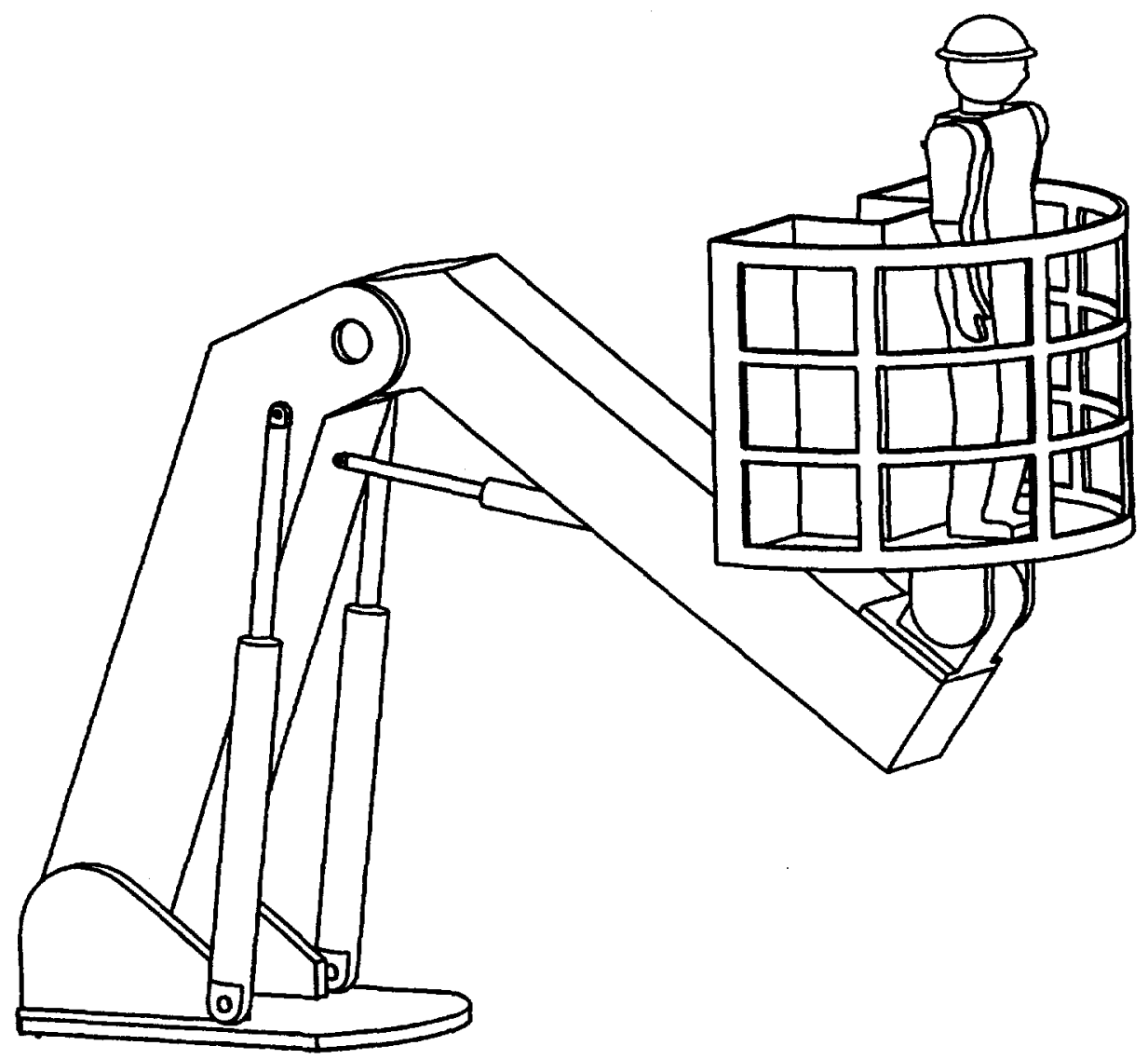

Figure 3.2.1.4.1.06 Preliminary Target Chamber Robot with Man Lift End Effector

\subsection{Plenum Cover Installation}

The pedestal lift shall be capable of placing the plenum cover at the bottom of the plenum to allow for vacuum to be placed on the chamber. This will be primarily a manual operation with autonomous safety checks. 


\subsection{Facility Considerations}

The robot shall be stored within the diagnostics building and transported via a cart to the lift when needed. The robot shall enter the pedestal through a fixed.opening at the bottom of the pedestal.

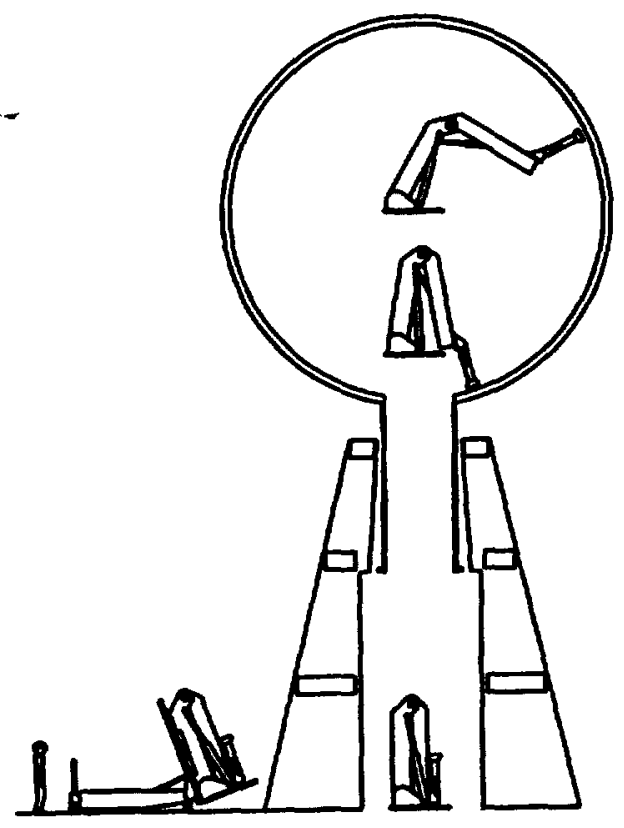

CLEANING

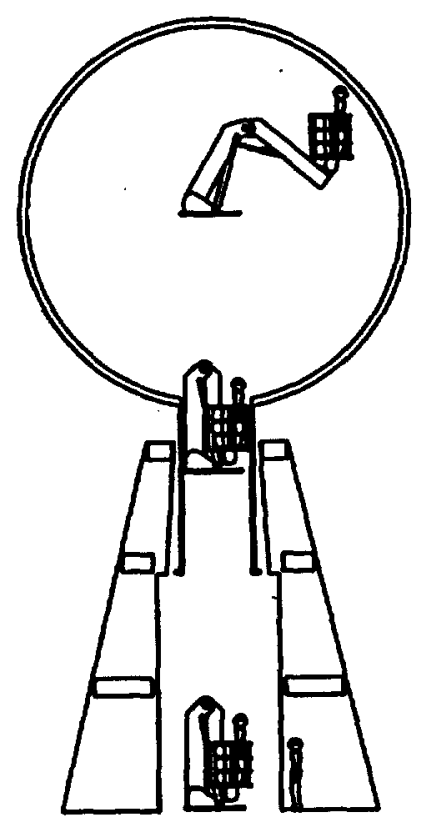

MAN LIFT

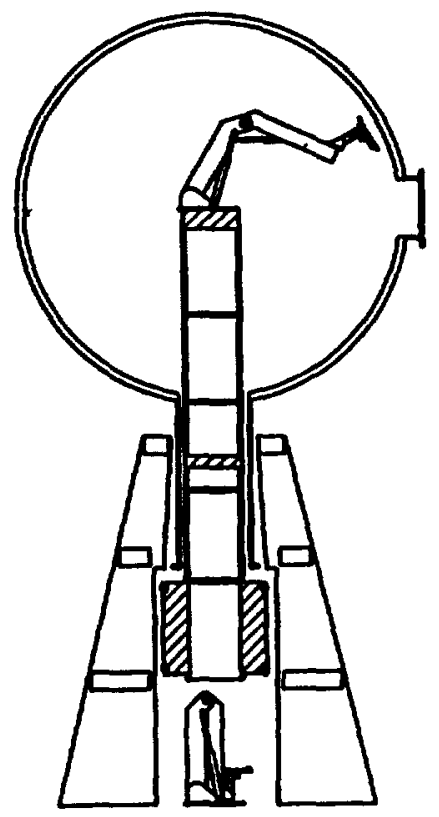

TILE MAINTENANCE OR

FOA COVER HANDLING

Figure 3.2.1.4.1.08 Preliminary Target Chamber Robotic Manipulator Tasks

\subsection{Remote Operation}

The robot shall be operated from a remote control room located in the diagnostics building. Video and lighting shall be placed within the chamber during operation. The robot controller shall posses redundant collision avoidance capability. Operation shall be performed by NIF technicians trained for robot use.

\subsection{Construction / Maintenance}

The robot should be maintainable as a standard industrial mechanism where possible. It shall be capable of withstanding cleaning in the general decontamination work station (GDWS) on a regular basis for removal of contamination. The chamber lift shall be maintainable after the NIF is completed. 


\subsection{Lift Storage / Installation}

The chamber lift shall retract below the basement floor within the target pedestal. The floor interface shall allow access and transport through the pedestal. The telescoping lift shall contain all cabling internally and facilitate quick robot connection on the lift table
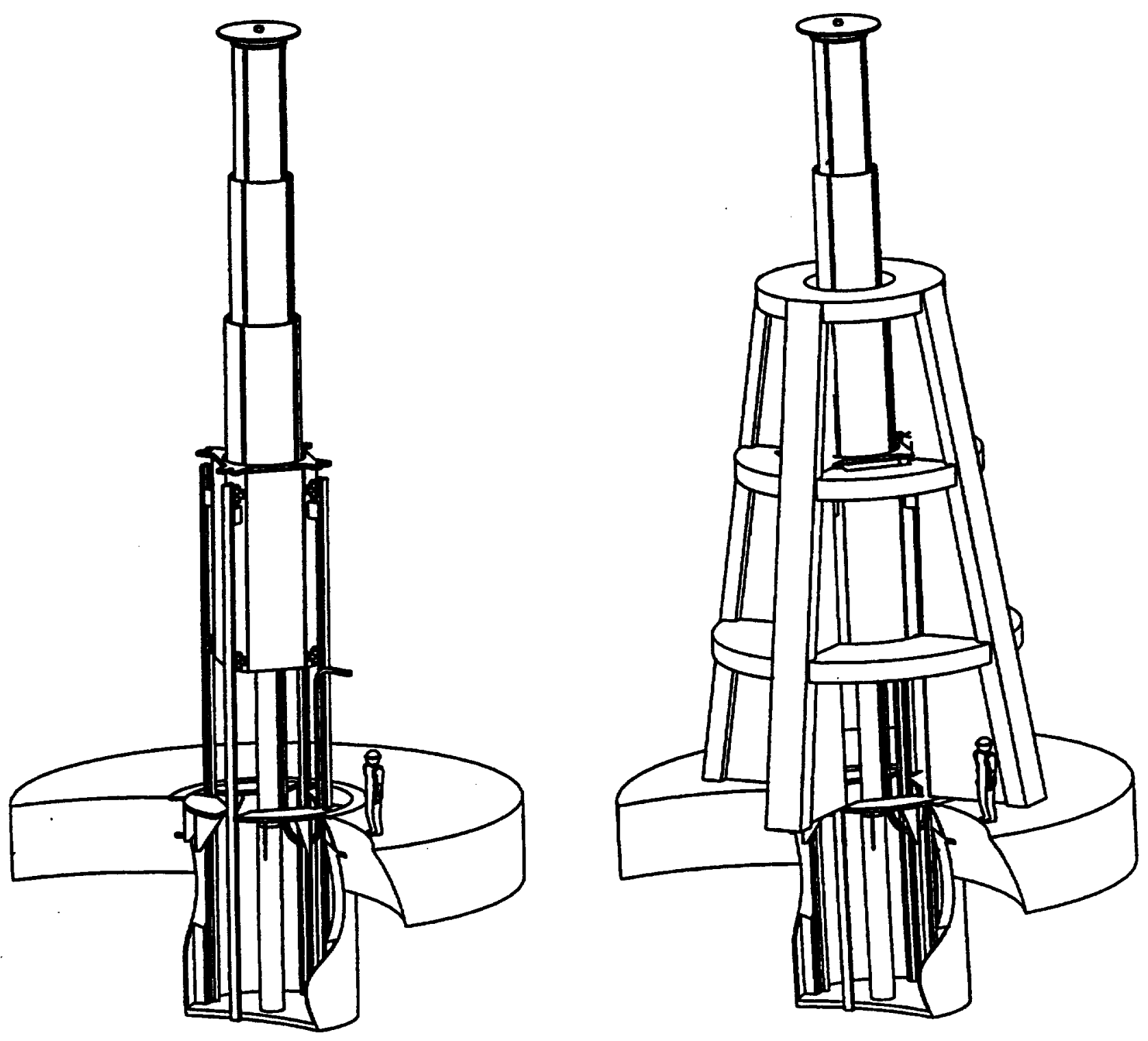

Figure 3.2.1.4.1.11 Preliminary Target Chamber Lift 


\subsection{Target Bay Service Systems Performance}

3.2.1.4.2.01 Final Optics Assembly Transport

The Final Optics Assembly (FOA) lifting equipment and fixtures shall be designed to remove and replace all FOA Integrated Optics Module (IOM) and all FOA Debris Shield (DS) LRU's.

3.2.1.4.2.02 Beam Tube Transport

The beam tube lifting equipment and fixtures shall be designed to remove and replace all beam tube LRU's.

\subsection{Diagnostic Transport}

The diagnostic lifting, fixture, and transport equipment shall be designed to remove and replace all diagnostic LRU's.

\subsection{First Wall Panel Transport}

The first wall panel lifting equipment and fixtures shall be designed to transport all first wall panel LRU's.

\subsection{LRU Adjacencies}

As a design goal, all LRU lifting equipment and fixtures should be designed to remove and replace a LRU with minimum disturbance of adjacent equipment.

\subsubsection{Physical Characteristics}

Not Used.

\subsubsection{Reliability, Availability, Maintainability (RAM)}

\subsubsection{Lifetime}

The Target Area Auxiliary Subsystems shall be designed to operate for 30 years.

\subsubsection{Replaceability}

Any portion of the Target Area Auxiliary Subsystem which cannot reasonably be designed for 30 year lifetime shall be designed to be replaced or repaired at reasonable cost in a timely manner consistent with the overall availability of the Target Area Auxiliary Subsystem and annual maintenance budget allocations.

\subsubsection{Reliability}

The Target Area Auxiliary Subsystem shall have an overall reliability of TBD\%. Reliability is defined as the probability of meeting the minimum requirements of the experiment per no-yield shot.

\subsubsection{Inherent Availability}

The Target Area Auxiliary Subsystem shall have a shot availability of at least TBD\%. The system is unavailable when it is undergoing unplanned maintenance. Unplanned maintenance includes failure detection and active repair as well as logistic and administrative downtimes.

\subsubsection{Maintainability}

The Target Area auxiliary Subsystem shall have a scheduled maintenance plan that fits within an overall annual plant goal of 69 days. The unplanned maintenance goal is TBD days per year. Opportunistic maintenance activities are performed between shots and during other system downtimes. 


\subsubsection{Recovery From Abnormal Events}

The time required for the Target Area Auxiliary Subsystem to recover from any abnormal event shall be less than the maximum times cited below, as a function of the expected yearly frequency of occurrence of the event.

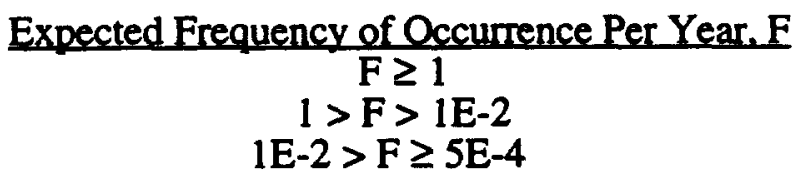

Maximum Recovery Time
24 hours
1 week
3 months

Probabilities listed in DOE-STD-1020-94 shall be used for natural phenomena.

\subsubsection{Environmental}

The site for NIF has not yet been selected. The present design is therefore non-site-specific. For the purpose of Title I design of the Target Area Auxiliary Subsystem, it shall be assumed that NIF will be constructed at a site with the general infrastructure as available at candidate sites. Specific environmental assumptions are listed in the following sections.

\subsubsection{Ambient Temperature/Humidity}

All Target Area Auxiliary Subsystem components within the target area building shall meet all requirements when operated at a temperature of $20 \mathrm{C} \pm 0.3 \mathrm{C}$, a relative humidity of $30 \%$ to $60 \%$, and a pressure equal to ambient atmospheric pressure $\pm 10 \mathrm{~cm}$ water (to accommodate negative air system). Any Target Area Auxiliary Subsystem components normally operated outside the target area building shall meet all requirements when operated between $-4.4 \mathrm{C}$ (dry bulb, winter) and $20.6 \mathrm{C}$ (wet bulb, summer) or 37.8 C (dry bulb, summer), and local atmospheric pressure.

\subsubsection{Ambient Vibration}

The Target Area Auxiliary Subsystem shall meet all requirements, while being exposed to ambient random vibration of $1 \mathrm{e}-10 \mathrm{~g}^{2} / \mathrm{Hz}$, from 1 to $200 \mathrm{~Hz}$, applied at the floor surface of the foundation of the target area building.

\subsubsection{Ambient Cleanliness}

The Target Area Auxiliary Subsystem shall meet all requirements when operated within the NIF LTAB. The ambient cleanliness levels in pertinent areas of the LTAB are as follows:

\begin{tabular}{lc} 
Area Ambient & Cleanliness Class \\
\hline Laser Bay & 100,000 \\
Switch yard & 100,000 \\
Target Bay & 100,000
\end{tabular}

\subsection{Design and Construction}

The Target Area Auxiliary Subsystem will prepare detailed designs and specifications as construction documents. All equipment and materials will be described in detail in the specifications. Construction will be per design and specifications and per acceptable industry standards. All installed systems will be tested for final acceptance for performance requirements.

\subsubsection{Hazard Classification}

The Target Area Auxiliary Subsystem shall be designed, constructed, and operated as part of the NIF such that it is a low-hazard, radiological component of the NIF. 


\subsubsection{Safety}

Unless otherwise specified herein, all elements of the Target Area Auxiliary Subsystem shall meet the requirements of the LLNL Mechanical Engineering Design Safety Standards, LLNL Electrical Engineering Design Safety Standards, and the LLNL Laser Safety Standards.

\subsubsection{Life Safety}

The Target Area Auxiliary Subsystem shall comply with the life safety requirements in DOE Order 420.1, Facility Safety. The target area auxiliary subsystems shall have adequate means of egress, protection of vertical openings, travel distances, capacities, and emergency lighting.

\subsubsection{Construction \& Occupational Safety}

Construction safety shall comply with the requirements of 29 CFR 1926, OSHA and DOE Order 440.1, Worker Protection Management for DOE Federal and Contractor Employees.

Industrial hygiene and occupational safety shall comply with the requirements of 29 CFR 1910, OSHA and DOE Order 440.1, Worker Protection Management for DOE Federal and Contractor Employees.

\subsubsection{Fail-Safe Design}

Wherever reasonably possible, the Target Area Auxiliary Subsystem shall be designed to fail safe upon inadvertent loss of power, accidental breach of isolated areas, or other failure.

\subsubsection{Robotic Systems Safety}

Robotic systems within the Target Area Auxiliary Subsystem shall comply with the requirements of ANSI/RIA R15.06 1992, American National Standard for Industrial Robots and Robot Systems - Safety Requirements.

\subsubsection{Human Factors}

The Target Area Auxiliary Subsystem shall be designed in an ergometric fashion to ensure that human reliability during operation and maintenance is sustained at a level consistent with meeting overall availability and reliability objectives. Consistency in displays, warnings, and human interfaces should be maintained throughout the target experimental system and if possible throughout the NIF facility (i.e.: GUI displays, computer operating systems, computer systems, access ports, tooling, etc.).

\subsubsection{Supervisory Software Access to Distributed Control Points}

The Target Area Auxiliary Subsystem will have a control system which shall be designed to provide the local and remote control functions required for normal operation and maintenance. The Target Area Auxiliary Subsystem shall provide the NIF ICCS access to its control system as required.

Access to all distributed control points that are integrated into the control system shall be made by Front End Processors that implement the hardware-level interface to the control points. The FEP software shall implement those functional requirements that are determined by requirements analysis to be allocated to the FEP layer in the controls architecture. The requirements analysis shall be guided by the physical properties and performance constraints of the control hardware, and by those operational scenarios requiring operation independent of the supervisory software or locality of control. 


\subsubsection{Documentation and Records}

The Target Area Auxiliary Subsystem shall provide sufficient documentation to comply with the "NIF Quality Assurance Plan", and "DOE Order 5700.6C, Quality Assurance, Criterion-4 Documents and Records" which states: "Documents shall be prepared, reviewed, approved, issued, used and revised to proscribe processes, specify requirements or establish design. Records shall be specified, prepared, reviewed, approved, and maintained."

Examples of documents that should be controlled include drawings, analysis calculations, specifications, computer codes, purchase orders, vendor supplied documents, procedures, work records, test records, and data sheets. Revisions should be reviewed by the organizations that originally prepared and approved the documents. Controlled documents should be distributed to those doing the work.

\subsubsection{Design Process}

Design shall be carried out using sound engineering principles and appropriate standards. Design work including changes shall incorporate applicable requirements and design bases. Interfaces shall be identified and controlled. The adequacy of design products shall be verified or validated by qualified individuals other than those who did the work. Verification and Validation work shall be completed before approval and implementation of the design.

\subsubsection{Future Modifications and Upgrades}

As a design goal, the Target Area Auxiliary Subsystem should provide for future reconfiguration and modification at minimum cost and with minimum effect on the overall operation of the facility.

\subsubsection{Decontamination and Decommissioning}

The Target Area Auxiliary Subsystem design shall meet the requirements of DOE Order 420.1 and sitespecific requirements. The Target Area Auxiliary Subsystem shall include considerations to allow cost effective future decontamination and decommissioning (D\&D) of all components and equipment.

\subsection{Logistics}

\subsection{1 -Spare Equipment}

As a part of the design/construction project, the Target Area Auxiliary Subsystem shall provide an initial compliment of spare parts as required to activate the system.

\subsubsection{Maintenance Equipment}

As a part of the design and construction, the Target Area Auxiliary Subsystem shall provide all equipment required to inspect, service, clean, decontaminate, and maintain all of its components to meet the maintainability and availability requirements in \$3.2.3. Maintenance equipment shall include all handling fixtures, lifting equipment, and other special tools not otherwise available within NIF, that are necessary to perform any planned (scheduled or unscheduled) maintenance activity.

\subsection{Other \\ Not Used}

\subsection{Major Component Characteristics and Verification Not Used}


4.0 QA Provisions

Quality Assurance for the Target Area Auxiliary Subsystem will be determined by verification methods identified in $\$ 3$, in combination with the identified Quality Level for individual components.

\subsection{Q-Level Assigned}

\begin{tabular}{|c|c|c|c|c|c|}
\hline \multirow{2}{*}{$\begin{array}{l}\text { WBS } \\
\text { Element } \\
\text { Number }\end{array}$} & \multirow[t]{2}{*}{ WBS Element Title } & \multicolumn{3}{|c|}{$\begin{array}{l}\text { Assigned } \\
\text { Q-Level }\end{array}$} & \multirow{2}{*}{ Why Not Q-Level 3? } \\
\hline & & 1 & 2 & 3 & \\
\hline 1.8.6.1 & Local Utility Services & & & $\sqrt{ }$ & \\
\hline 1.8 .6 .2 & Cable Trays & & & $\sqrt{ }$ & \\
\hline 1.8.6.3 & $\begin{array}{l}\text { Personnel, Safety, and } \\
\text { Occupational Access }\end{array}$ & & $\sqrt{ }$ & & $\begin{array}{l}\text { Failure of the Oxygen or Carbon Dioxide } \\
\text { monitors could result in asphyxiation of } \\
\text { workers. }\end{array}$ \\
\hline 1.8.6.4.1 & $\begin{array}{l}\text { Target Chamber } \\
\text { Service System }\end{array}$ & & & $\sqrt{ }$ & \\
\hline 1.8 .6 .4 .2 & $\begin{array}{l}\text { Target Bay } \\
\text { Service Systems }\end{array}$ & & & $\sqrt{ }$ & \\
\hline
\end{tabular}

\subsection{Quality Requirements}

Reserved

\subsection{Quality Assurance Measures (verification requirements)}

Reserved Used

\section{$5.0 \quad$ Notes}

Not Used

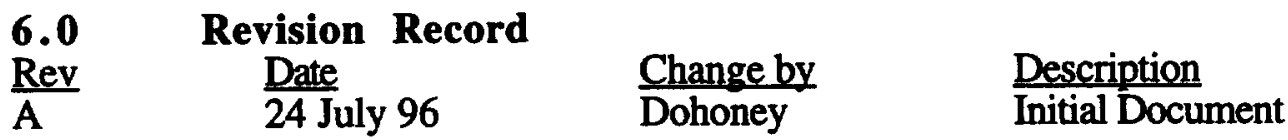

\begin{tabular}{|l|l|l|l|l}
\hline Rev & Date & ECR\# & B y & Description of/Reason for Change \\
\hline A & $8 / 23 / 96$ & n/a & Dohoney & inital Title I issue \\
\hline B & $10 / 20 / 96$ & 76 & Dohoney & correct EMI protection to only diagnostic cable trays \\
\hline
\end{tabular}




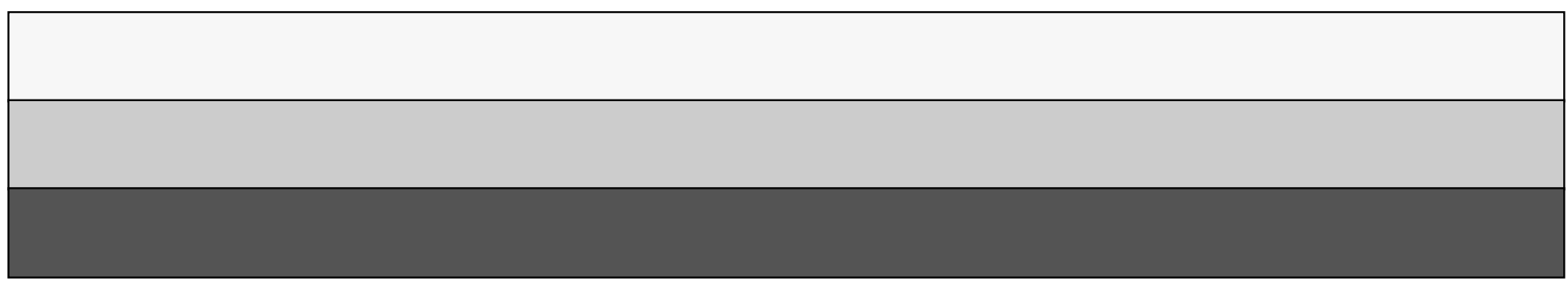

